\title{
The Paradox of Employee Age: An Empirical Investigation of the Role of Age and Employee Outcomes in Kenyan Public Corporations
}

\author{
Stella Moraa Omari, Peter K’Obonyo and Harriet Kidombo
}

\begin{abstract}
Age may refer to the length of time an organism has lived. Ageing in human beings refers to a multidimensional process of physical, physiological and social change. It is important in all human societies not only reflecting the biological changes that occur but also reflecting cultural and societal conventions. This study limited itself to chronological ageing referring to how old a person is. This can be clearly distinguished from social ageing which refers to society's expectations of how people should act as they grow older. It is also distinguishable from biological ageing which refers to an organism's physical state as it matures. The demographic variable of age has some distinct attributes within the organizational context. It is important because of its linkage to individual experience and personal accumulated knowledge. Age levels vary widely within organizations, in that individuals start jobs in their late teens and do not retire until their mid-fifties or sixties. Employee age correlates positively with advancement within the organization. Age in organizations, elicits various responses. Higher level positions are often associated with increased responsibility and authority. Organizational policies are such that employees advance upward as they obtain experience and prove themselves in less responsible jobs. Therefore, in many decisions affecting employees, age seems to feature in one way or another (Ekamper, 1997). The study looked at employee age as an independent variable and whether it affects employee outcome of job satisfaction, commitment, trust and organizational citizenship behaviours. Previous studies had shown that employee age is a strong predictor of these outcomes however the study found age to have very little or no significant relationship with employee outcomes.
\end{abstract}

Key Words: Employee age, Employee outcomes

\section{Introduction}

Age may refer to the length of time an organism has lived. Ageing in human beings refers to a multidimensional process of physical, physiological and social change. It is important in all human societies not only reflecting the biological changes that occur but also reflecting cultural and societal conventions. This study limited itself to chronological ageing referring to the number of years a person has lived. This can be clearly distinguished from social ageing which refers to society's expectations of how people should act as they grow older. It is also distinguishable from biological ageing which refers to an organism's physical state as it matures. The demographic variable of age has some distinct attributes within the organizational context. It is important because of its linkage to individual experience and personal accumulated knowledge. Age levels vary widely within organizations, in that individuals start jobs in their late teens and do not retire until their mid-fifties or sixties. Employee age correlates positively with advancement within the organization. It's been found that a long-term experience may influence attitudes and belief systems which can be substantially different across age groups (Edgar \& Geare, 2004). Age in organizations, elicits various responses. Higher level positions are often associated with increased responsibility and authority. Organizational policies are such that employees advance upward as they obtain experience and prove themselves in less responsible jobs. There is also the political element that determines who gets which jobs in the organization. Therefore, in many decisions affecting employees, age seems to feature in one way or another (Guest \& Conway 2002, Smithson \& Lewis, 2000, Ekamper, 1997).

Scott and Cook (1981) identified chronological age as one of the single most useful piece of information about an individual. Based on age; inferences about a person's anatomy, attitudes and social behaviour can be made. Furthermore, strong societal expectations exist concerning the behaviours of different age groups. It is suggested, therefore, that the reactions of different age groups to the introduction of change in an organization will vary significantly. The definition of age at which a worker is considered old varies although 45 years and over is commonly used. The age of 45 years as an age at which a worker can be classified as 'older' is consistent with the World Health Organization Report of 1993.

Effective HRM is no longer concerned with simply executing a standard set of policies and procedures. Rather, it requires questioning and understanding the relationships between choices in managing people, the strategies and goals of the organization and the possibilities presented by the external environment. Interest in the belief that individual employee performances affect organizational outcomes has intensified with the argument that an organization's employees provide a unique source of competitive advantage that is difficult for competitors to replicate (Roos, Fernstrom \& Pike, 2001). Employee outcomes as defined by job satisfaction, 
trust, organizational citizenship behaviours and commitment have far reaching impacts on business performance. Trust has been found to be a necessary element for open accurate communications. It influences the effectiveness of group problem solving and decision making as well as people's attitudes and feelings about the organization and their jobs and ultimately impacts human resource performance (Scott \& Cook, 1981).

Job satisfaction is described as the pleasurable feeling arising from one's workplace (Silva, 2006). Different degrees of importance are given to various sources of job satisfaction. These sources can be classified as intrinsic or extrinsic. Intrinsic sources depend on the individual characteristics of the person. In the study, it was argued that the intrinsic characteristic of age would influence job satisfaction. One's age contributes to job satisfaction in that individual experiences pre-dispose one to be satisfied or not satisfied with their job. Age can influence satisfaction based on prior experience and the resulting consequences. Particular organizational situations may trigger satisfaction or dissatisfaction. This relationship will be moderated by the contextual and cognitive factors and ultimately impact employee outcomes.

Employees experience job satisfaction if they perceive that their abilities and competence are put to use in the organization and if they receive both rewards and further opportunities from the organization. Bernal et al (2005) says that organizations cannot reach competitive levels of quality either at product level or customer service level if their personnel do not feel satisfied or do not identify with the company. Satisfaction is the final state of a psychological process. Job satisfaction is the degree to which a person feels satisfied by their job which has an impact on personal well being and on the life satisfaction of the employee. It is a multidimensional concept that includes favourable and unfavourable feelings by which employees perceive their job.

Organizational commitment is a set of behavioural intentions, a motivating force or an attitude which influences many behavioural and attitudinal outcomes. Committed employees are deemed as those who share the common values and beliefs espoused by the organization. They have a willingness to not only remain with their employer but a strong desire to exert effort for the organization. Committed employees believe that their organizations have satisfied their expectations. Commitment has been found to be a predictor of various outcomes such as turnover, intention to leave and absenteeism. It is a manifestation of the individual's existence as a person characterized by; a strong belief in and acceptance of the organization's goals and values, a willingness to exert considerable effort on behalf of the organization and a definite desire to maintain organizational membership. Committed workers contribute more to the organization than less committed ones.

Organizational commitment is a consequence of personal variables, role states and work environment variables. Therefore, employees experiencing perceived injustice or psychological contract violation may be less committed (Elizur \& Kaslowsky, 2001; Foote, Seipel, Johnson \& Duffy, 2005; Lin \& Chang, 2005; Singh \& Vinnicombe, 2000). Organizational commitment and job satisfaction have been found to be significantly related to one another with the basic proposition that job satisfaction is an antecedent of organizational commitment since commitment takes longer to form and only after one is satisfied with their job (Silva, 2006). Employees may interpret the support provided by their employer as a commitment towards them and this in turn enhances their commitment to the organization (Aube et al, 2007). Commitment is the degree of identification and involvement which individuals have with their organizations. It translates into their desire to stay with the organization, believe in its objectives and the willingness to work hard on behalf of the organization in the pursuit of business objectives (Price, 2007). Commitment is identified as both an antecedent and a consequence of various work related variables. It is also presented as a consequence of personal variables (Foote et al, 2005). Thus it is presumed that employee age a personal variable will influence organizational commitment.

Murphy et al (2002) defined Organizational Citizenship Behavior (OCB) as discretionary organizational behavior not explicitly recognized by the formal reward system, which is pro-social that is, it promotes the effective functioning of the organization. They found a strong correlation between internalization and pro-social organizational behaviors involving the expenditure of personal (that is, extra-role) time and effort. Organizational citizenship behavior is generally considered to consist of five dimensions: altruism, courtesy, sportsmanship, conscientiousness, and civic virtue. Altruism and courtesy are helping behaviors directed toward a specific person, and sportsmanship is complaining behavior (or the lack thereof) directed toward supervisors. However, conscientiousness involves behaviours that go above and beyond the requirements of both formal and informal rules, and civic virtue implies a sense of involvement in what policies are adopted. Consequently, this study focused on how age influences these behaviours among employees.

Employees in organizations do exhibit individual behaviour that is discretionary, not directly or explicitly recognized by the formal reward system and that in the aggregate promotes the effective functioning of the organization (Podsakoff, Mackenzie, Paine \&Bachrach, 2000). There are various antecedents of OCB and empirical research has focused on four major categories of antecedents. These are individual characteristics, task characteristics, organizational characteristics and leadership behaviour (Podsakoff et al, 2000). In the current study, the individual characteristic of age was presumed to influence OCB in the organization. It is further presumed that this relationship will be moderated by justice, psychological contract, attribution and contextual practices. 
Interpersonal trust is a key ingredient in cooperative relationships. The formation of trust is often the focus of organizational development efforts. High levels of trust are associated with efficient work group functioning, long term organizational effectiveness and the willingness of people to adapt to change (Scott \& Cook, 1981). Trust is therefore characterized as the positive force from which cooperation is derived. Trust in another party reflects an expectation that the other party will act benevolently, no force or control of the other party and it involves some level of dependency on the other party (Whitener, Brodt, Korsgaard\& Werner, 1998). Managerial trustworthiness as perceived by the employee is captured by these factors, behavioural consistency and integrity; sharing and delegation of control; demonstrated concern and communication that is accurate and transparent.

\section{Age and Contextual factors}

Aube et al (2007) argue that individual differences may influence reactions to change and, ultimately, commitment to the organization. For example, individuals highly tolerant of ambiguity should be better equipped to handle the uncertainty associated with organizational change. Similarly, individuals high in openness to experience and high self-monitors should react more positively to organizational change efforts. Thus, a complete model of change should address not only macro-level forces such as content, process, and contextual factors, but also micro-level factors such as individual differences. Employees are less sensitive to the support provided by their organizations when personal or contextual factors lead them to believe they can exercise control over their work environment.

Aggarwal \& Bhargava (2009) stated that contextual performance refers to behaviours that support the organization, psychological and social context in which tasks are performed. It is distinct from task performance which relates to technical behaviours involved in the application of technical skills and knowledge (Bradley, Bish \& Sargent, 2004). Therefore, it is critical that a firm employs human resource practices that encourage consistent engagement in high levels of contextual performance behaviours. These include organizational systems and processes such as remuneration and rewards and transparency of Human resource Management (HRM) practices. HRM practices can be seen as an agent of the organization, through which an individual forms perceptions of support, fulfilment and organizational justice/fairness. Reward management, performance management and organizational culture are an important inducement of the exchange process between employers and employees as they influence the structural signals about constructs.

\section{Problem Statement}

All changes that take place in the environment are translated by employees and given individual meaning according to the understanding of the person experiencing them. The cognitive processes of attribution, organizational justice and psychological contract in this study contribute greatly to assigning meaning to the experiences encountered. Chronological age has allowed different mental schemas to develop uniquely with time in each individual and management may not do much to influence or change them. In other words, employees are not a homogeneous group with similar attitudes and beliefs. There are so many issues that can be inferred just by knowing someone's age. In human resource management the influence of age is more pronounced in recruitment and promotion. The influence of age as moderated by contextual and cognitive factors on employee outcomes has not been studied. This study was motivated by the need to fill this gap. At the same time, studies on the influence of contextual and cognitive factors on the relationship between age and employee outcomes are not many, especially in Kenya. Many studies have been done on age and its influence on employee outcomes in Europe, America and Asia (Nirmala \& Akhilesh, 2006; Nurse \& Devonish, 2007; Pate et al, 2003; Rahim, Magner, Antonioni \& Rahmanl, 2001; Suazo, 2009) but there are not many studies that how these relationships are moderated by contextual and cognitive factors.

Studies on the direct relationship between age and employee outcomes that is satisfaction, commitment, trust and organization citizenship behaviours have found that age explains only a small percentage of variance in the outcomes. The correlation coefficient ( $r$ ) for the relationship between age and employee outcomes such as job satisfaction, commitment, trust and citizenship behaviour ranges from 0.26-0.40 (Cassar $2001 \mathrm{r}=0.37$, Ekamper 1997, Oshagbemi $2004 \mathrm{r}=0.30$, Taormina $1999 \mathrm{r}=0.26$, Lemire and Rouillard, 2005 $\mathrm{r}=0.40$ ). As can be observed from these correlation coefficients the relationship between age and employee outcomes is relatively weak. Since age has been found to be a weak predictor variable of employee outcomes, it is possible that there are other factors that contribute to changes in employee outcomes. the study therefore focused on the moderating role of cognitive and contextual factors to find out whether these offer an explanation for changes in the relationship between age and employee outcomes.

\section{Methodology}

The research was guided by the positivist philosophy of science. The positivist paradigm is a research orientation which assumes that a useful research is based on theory, hypotheses and quantitative data. The researcher is an objective analyst who makes interpretations about the collected data in a value-free manner 
(Bryman, 2001). Descriptive surveys fall within the positivist philosophy of research as they seek to use quantitative techniques in analyzing social phenomena. Positivism was appropriate for the study as there was observer independence, choice of what to study was determined by objective criteria and not human belief and the expectation that the results would be generalized to the target population. A descriptive survey design was used and the data collected was cross-sectional. The choice of this design was guided by the purpose of the study which was to compare individual employees in terms of their job satisfaction, commitment, trust and organizational citizenship behaviours as influenced by employee characteristics such as age, locus of control, gender and education. The moderating role of contextual and cognitive factors in this relationship was also considered. The study was also guided by the type of investigation which was cross-sectional. The study sought to establish associations among these variables and estimate proportions in the population.

The population of the study comprised all the employees of public corporations. The sampling unit for the study was employees. The sample design used was proportionate stratified random sampling technique. This sample design was chosen in order to ensure representativeness of the population and thus generalizability of the results. The sample size for the study was 384 employees. This sample size was determined using a table developed by Krejcie and Morgan (1970). This table is used to determine sample sizes assuming a confidence level of $p \leq 0.05$ implying confidence that 95 percent of the time the study's findings from different samples of the same size from the same population will be wrong due to sampling error with only five percent of the samples. The total number of employees in the state corporations in 2006 was 86876 . These numbers were not exact and determining the exact population would have been costly and timing consuming. A sample size of 390 respondents was chosen from 13 corporations representing all the eight sector categories of public corporations. Data was collected using structured questionnaires developed on a five-point Likert scale. Age data was collected as part of demographic data filled in by respondents using class intervals. Adopting questionnaires from previous studies allowed for reliability to be assessed. To find out the reliability of the instruments in the study, pilot testing was done on twenty respondents to pre-test the instruments and then Cronbach's alpha was calculated. The reliability measure lies on a scale from 0 to 1 . The reliability coefficients in the study for the instruments ranged between $0.6-0.92$ demonstrating an acceptable level of reliability.

\section{Results of the Study}

Table 1: Distribution of Respondents by Age Group

\begin{tabular}{lll}
\hline Age group & Frequency & Percent \\
\hline $18-30$ & 33 & 18.2 \\
$31-44$ & 104 & 57.5 \\
$45-55$ & 41 & 22.7 \\
Over 55 & 3 & 1.7 \\
\hline Total & 181 & 100.0 \\
\hline
\end{tabular}

Source: Research Data (2010)

Table 1 indicates that more than 57.5 percent of the respondents are between the ages of 31-44 years. The age group of $45-55$ years represented 22.7 percent of the respondents. 18-30 years comprised 18.2 percent of the respondents while those over 55 years of age represented 1.7 percent of the respondents. Majority of the respondents are at a very active age where most people are sure of what they want from life. It is also the age range at which most people seek advancement, growth, security and are thinking of adopting a lifestyle based on their careers. They also tend to view their counterparts as colleagues. It is assumed that these features of this particular age group can have an effect on the perceptions of the contextual and cognitive factors and eventually impact their attitudes and behaviours in the organization.

Those in the 45-55 years age bracket tend to hold on to accomplishment and are more inclined to maintaining whatever they have. In relation to this study they are presumed to be more sensitive to any developments that seem to change the old order of things. Those in the 18-30 years age group are characterized by the fact that they are still identifying their career interests and also exploring how well they fit into their work. They may not be affected much on their perceptions of the cognitive and contextual factors as they are still exploring and are at the entry level of their careers or working life. Those who are more than 55 years of age are preparing for concluding their organizational life. It is assumed that they may not be very keen on what happens in the organization as they are already phasing out. This near balanced age distribution allowed the study to assess whether age is a significant factor in influencing employee outcomes of trust, satisfaction, commitment and citizenship behaviour. To allow for this data to be used in further analysis age was collapsed into two categories of younger and older workers as shown in Table 2 . 
Table 2: Distribution of Employees' Age in Two Categories (Younger and Older)

\begin{tabular}{lll}
\hline Age Group & \multicolumn{2}{c}{ FrequencyPercent } \\
\hline $18-44$ - Younger Employees & 137 & 75.7 \\
45 and over - Older Employees44 & 24.3 \\
\hline Total & 181 & 100.0 \\
\hline
\end{tabular}

Source: Research Data (2010)

\section{Hypotheses of the Study}

Employees interpret the information that they receive and the experiences they undergo in the organization. There are possibilities of similarities in people's perceptions because of the common work situation. However, different ages evoke different levels of encounter with organization, because older employees have clarity of expectations as compared to younger ones. This means that any changes that affect employees may cause a major shift in the perceptions of justice, causal attributions and contractual expectations. The vigilance of employees may increase and any acts from management receive extra attention and this can affect the employee outcomes. Prior experience and HR practices greatly influence employees' interpretation of the events in their work situation. Given this scenario the following hypotheses were drawn:

H1: There is a relationship between employee's age and employee outcomes.

H2: The strength of the relationship between employees' age and employee outcomes depends on the context. H3: The strength of the relationship between employees' age and employee outcomes depends on attribution These hypotheses were to elaborate the research objective that sought to establish the nature of the relationship between employee age and employee outcomes.

\section{Relationship between Age and Employee Outcomes}

Objective one of the study was to establish the nature of the relationship between employee age, and employee outcomes. To analyze data for this objective, Pearson Product Moment Correlation technique was used.

H1: There is a relationship between age and employee outcomes (trust, commitment, and organizational citizenship behaviour and job satisfaction)

Data used to test this hypothesis were obtained by asking respondents to rate the items on the questionnaires on job satisfaction, organizational commitment, OCB and employee trust. To find out the relationship between age and employee outcomes, correlation was done using Pearson's Product Moment Correlation technique. The output of the correlation is shown in Table 3.

Table 3: Pearson's Product Moment Correlation Coefficients for the Relationships between Age and Employee Outcomes

\begin{tabular}{llll}
\hline Variables & $\mathbf{N}$ & $\mathbf{r}$ & $\mathbf{P}$ \\
\hline Employee trust and age & 178 & -.019 & 0.799 \\
Organizational citizen behaviour and age & 176 & .044 & 0.562 \\
Job satisfaction and Age & 178 & .055 & 0.465 \\
Organizational commitment and Age & 178 & & \\
\hline Data $(2010)$ & & -.064 & 0.399 \\
\hline
\end{tabular}

Source: Research Data (2010)

The results in Table 3 show that correlations between age and the various employee outcomes were not significant. The $\mathrm{p}$-values for the Pearson product moment correlation coefficients were all greater than $.05(\mathrm{r}=-$ $.019, .044, .055, .064 \mathrm{P}>0.05)$. These results imply that age did not have statistically significant effects on any of the employee outcomes suggesting that employee age does not determine employee outcomes. Based on these findings, it is noted that the relationship between age and employee outcomes is not significant; hence the hypothesis that there is a relationship between age and employee outcomes is not supported. This finding is discussed below.

\section{Discussion for the Relationship between Age and Employee Outcomes}

The hypothesis developed under this objective stated that a relationship exists between employee's age and employee outcomes. The data presented in table 3 shows that the relationship between age and employee outcomes (job satisfaction, commitment, organizational citizenship behaviour and employee trust) is not statistically significant at $\mathrm{p}<0.05$. This result is similar to results obtained by Tu, Plaisent, Bernard and Maguiraga (2005). In their study of age and job satisfaction of faculty at higher education level in China and 
Taiwan, they found no statistically significant relationships between age and job satisfaction. The present findings were also similar to those found by Green Jr. et al (2005) in their study of relational differences between supervisors and their subordinates in a dyad. Specifically they found that overall age did not impact on job satisfaction and commitment.

However, the results of this study differ from those found by Hickson and Oshagbemi (1999) which indicated a positive relationship between age and satisfaction of teaching faculty in higher education. They also differed with the findings of Scott and Cook (1981) who found that a relationship exists between age and trust. The results of the present study were not statistically significant for the relationship between age and OCB. Previous studies had not tested this particular relationship as most of them considered the relationship between personal dispositions and OCB. The relationship between age and employee OCB had not been studied before. Most previous studies concentrated on the relationship between age and job satisfaction and/or organizational commitment. Thus, by exploring this relationship this study has gone a step further in enhancing knowledge on this relationship. OCB are more affected by organizational climate which may be the reason age does not affect the employees' perceptions of OCB.

Age may not have had significant relationships with the employee outcomes because by itself, it may not be an antecedent influence on employee outcomes. This implies that there are factors not inherent in the individual that influence outcomes. Another plausible explanation for the research findings being different from those that found a significant relationship could be attributed to country settings. The studies that found significant relationships were based in countries where age discrimination issues are more explicit hence causing the people to pay more attention to issues of age than situational factors. The fact that these results are obtained in a different context - Kenya, means that the present research has made a significant contribution to the existing body of knowledge.

\section{Age, Contextual Factors and Employee Outcomes}

Another objective of the study was to establish the moderating role of contextual factors in the relationship between employee age and employee outcomes. There was one hypothesis tested for this relationship using stepwise multiple regression. The regression was done for age and contextual variables namely, organization size and HR practices with employee outcomes.

H2: The strength of the relationship between employees' age and employee outcomes depends on the context. The findings are presented in Table 4

Table 4: Results for the Relationship between Age, contextual variables and Employee Outcomes

\begin{tabular}{|c|c|c|c|c|c|c|}
\hline Model & $\mathrm{R}$ & $\mathrm{R}^{2}$ & $\begin{array}{c}\text { Adjusted } \\
\mathrm{R}^{2} \\
\end{array}$ & $\mathrm{~F}$ & Beta & Predictor variable \\
\hline OCB & .200 & .040 & .012 & 1.405 & $\begin{array}{l}.174 \\
.159\end{array}$ & $\begin{array}{l}\text { HR Practices } \\
\text { Org. Size }\end{array}$ \\
\hline Trust & .317 & .100 & .074 & $3.797 *$ & .333 & HR Practices \\
\hline Job Satisfaction & .566 & .321 & .319 & $20.186^{*}$ & $\begin{array}{l}.221 \\
.452\end{array}$ & $\begin{array}{l}\text { Org. Size } \\
\text { HR Practices }\end{array}$ \\
\hline Organization Commitment & .339 & .115 & .090 & $5.565^{*}$ & $\begin{array}{l}-.258 \\
-.189\end{array}$ & $\begin{array}{l}\text { HR Practices } \\
\text { Org. size }\end{array}$ \\
\hline
\end{tabular}

Predictors: (constant), age, HR practices and organization size *Model significant at $\mathrm{P}<0.05$ level

Multiple regression was performed to determine the best linear combination of organization size, HRP and age for predicting employee outcomes. This combination of variables significantly predicted change in employee trust $\left(\mathrm{F}_{5,175}=3.79 \mathrm{p}<0.05\right)$, Job satisfaction $\left(\mathrm{F}_{5,175}=20.19 \mathrm{p}<0.05\right)$, and organizational commitment $\left(\mathrm{F}_{5,175}=\right.$ $5.57 \mathrm{p}<0.05$ ) with all the variables significantly contributing to the prediction. The $\mathrm{r}$ values in table 4 show that the model explained 31.7 percent, 56.6 percent and 33.9 percent of the relationship between age and trust, job satisfaction and organizational commitment respectively.

The beta weights presented in table 4 suggest that HR practices and organization size contributed significantly to moderating the relationship between age and employee outcomes. The $\mathrm{F}$ values indicate that HR practices and organization size contributed significantly to the moderation of the relationship between age and employee outcomes. They further indicate that HR practices have a large impact on employee job satisfaction, commitment and trust. The model for OCB was not statistically significant even though the $r$ value shows that the model accounted for twenty percent of the variance in OCB. The beta values were significant with HR practices contributing 17.4 percent to the change in OCB while organization size contributed 15.9 percent of the variance. 


\section{Discussion on Age, Contextual Variables and Employee Outcomes}

Hypothesis Two stated that the strength of the relationship between employees' age and employee outcomes depended on the context. Multiple regression was performed to test this relationship. The results in Table 4 indicated that all the models were statistically significant except for the organizational citizenship behaviour (OCB) model. The beta values in Table 4 indicate that contextual factors had statistically significant contributions to the relationships between age and employee outcomes. This result in Table 4 demonstrates the moderating effect of organizational size in the relationship between age and employee outcomes. The study had three different sizes of organizations in terms of employee size. Small organizations employed less than 400 people; medium organizations had more than 401 people but less than 1000, while large organizations were those that had more than 1000 people. Organization size moderated all the relationships with employee outcomes and this is an area that was not covered in extant literature and therefore is a contribution to the body of knowledge. The relationship between age and employee outcomes was moderated by human resource practices as demonstrated in table 4 whereby the beta value for every model was significant on the contribution of human resource practices. This essentially implies that good and favourable HR practices are appreciated by all regardless of age. Considering that the HR practices covered in the study included aspects on communication, change practices, decision making, employee involvement and organizational pride we can conclude that all people across the age spectrum will appreciate all these factors when they are implemented well in any organization. Previous studies reviewed in the current study did not consider the influence of human resource practices on the relationship between age and employee outcomes. This therefore, is a contribution that the study made to the existing body of knowledge.

\section{Age, Cognitive Factors and Employee Outcomes}

A third objective of the study was to establish the moderating role of cognitive factors on the relationship between employee age and employee outcomes. The cognitive factors were organizational justice, psychological contract and attribution. These variables were measured on an interval scale. From the literature reviewed on empirical studies there was evidence that cognitive factors could influence employee outcomes. Three hypotheses were developed to test the relationship between age, cognitive factors and employee outcomes.

H3: The strength of the relationship between employees' age and employee outcomes depends on attribution

H4: The strength of the relationship between employees' age and employee outcomes depends on psychological contract perceptions

H3: The strength of the relationship between employees' age and employee outcomes depends on organizational justice perceptions

Table 5: Results for the Effect of Cognitive Factors on the Relationship between Age and Employee Outcomes

\begin{tabular}{llllll}
\hline Model & $\mathbf{r}$ & $\mathbf{R}^{2}$ & $\mathbf{F}$ & Beta & Predictor variables \\
\hline 1 & .390 & .152 & $7.185^{*}$ & .165 & $\begin{array}{l}\text { Psy. Contract } \\
\text { Org. Justice }\end{array}$ \\
2 & & & .289 & Org. Justice \\
3 & .273 & .075 & $3.225^{*}$ & .263 & - \\
4 & .142 & .020 & 0.818 & - & Attribution \\
& .499 & .249 & $13.339^{*}$ & .208 & Org. Justice \\
\hline
\end{tabular}

1 - Organizational Commitment, 2- Trust, 3- OCB, 4- Job Satisfaction $\quad * \mathrm{P}<0.05$

Predictors: Age, attribution, Psychological Contract, Organizational Justice.

The regression results presented in Table 5 show that 39.0 percent of the relationship between organizational commitment and age is explained by cognitive factors $(\mathrm{r}=0.390 \mathrm{P}<0.05) .27 .3$ percent of the relationship between age and trust was attributable to the cognitive factors, 49.9 percent of the relationship between age and employee job satisfaction was explained by cognitive factors. The relationship between age and OCB was not statistically significant as shown by model 3 .

Although employee age was one of the predictor variables in all the models, the beta coefficients in table 5 indicate that it did not have a statistically significant effect on any of the employee outcomes. From the beta coefficients in table 5 organizational commitment was influenced by psychological contract $(0.165)$ and organization justice (0.289). This implies that a change in organizational justice has a relatively larger effect on organizational commitment than that produced by a change in psychological contract. Trust was influenced by perceptions of organization justice (.263) while job satisfaction was influenced by attribution and (.208) and organization justice (.412). This implies that a change in organization justice will have a large effect on job 
satisfaction than attribution. The results in table 5 further indicate that OCB was not influenced by any of the cognitive factors as it did not have any statistically significant beta coefficients.

These results have implications for organizations because the cognitive predictors are all perceptual in nature and they impact work performance. These outcomes are a function of the individual subjective responses and although they are valuable they are not easily managed. It is imperative that the antecedents of these outcomes such as favourable human resource practices, fairness in resource allocation and interaction within organizations be properly managed to avoid negative outcomes. Organizational citizenship behaviours did not have any significant correlations with any of the cognitive factors. This finding contradicts the findings by Podsakoff et al (2000) which was the only study the researcher found that had fairness (organizational justice) as an antecedent of organizational citizenship behaviours.

Hypothesis 3 which stated that the strength of the relationship between age and employee outcomes depended on attribution was not rejected. The findings are presented in Table 5.17 and the following statistics; $\mathrm{r}=.387, .271, .136, .455$ for organization commitment, trust, OCB and job satisfaction respectively, show that attribution does have a significant influence on the relationship between age and employee outcomes. However, it is worth noting that when attribution was excluded from the job satisfaction model, the $r$ value changed significantly $(r=.499$ vs. $r=.455)$. This implies that the kind of attribution an individual gives to the causes of organizational events influences job satisfaction. Previous studies reviewed in the current study did not look at this relationship and therefore, this finding can be considered as an addition to the existing body of knowledge on the antecedents of job satisfaction.

Based on these findings, it is noted that the relationship between age and employee outcomes is significantly influenced by employees' perceptions of organization justice. This conclusion is based on the fact that when organization justice is included in the regression model, change in $\mathrm{r}$ was noticeable for all the four dependent variables. The $\mathbf{r}$ coefficients $(.279, .114, .125, .311$ vs. $.390, .271, .138, .499)$ and $\mathrm{F}$ ratios $(4.518$, $.700, .472,5.788$ vs. $7.185,3.243, .818,13.339)$ for all the regression models, also changed considerably. In this regard, the hypothesis that the strength of the relationship between age and employee outcomes depends on organization justice was confirmed.

Hypothesis $3 \mathrm{c}$ which stated that the strength of the relationship between age and employee outcomes depends on the psychological contract was rejected, implying that psychological contract does not influence the relationship between age and employee outcomes. The findings of the current study are presented in Table 5.21. The table shows that $\mathrm{R}^{2}=.152, .075, .019, .249$, for organization commitment, employee trust, OCB and job satisfaction respectively when psychological contract is included, $\mathrm{R}^{2}=.152, .074, .015, .247$, for organization commitment, trust, OCB and job satisfaction respectively when psychological contract is excluded. These results are not supported in extant literature. The existing literature did not consider age as a variable that could influence perceptions of the psychological contract.

However, Kidwell Jr. (2003) in his study on helping older workers cope with continuous quality improvement found that there were generational differences in the reactions of employees to major change initiatives. His study could not conclusively attribute perceptions of unfulfilled or violated psychological contract to employee age. Similarly, this current study fails to prove this and therefore more research is required. The current findings could be attributed to the fact that the current study used age in form of class intervals instead of asking for exact individual ages and hence it was not easy to see the variation in terms of responses. However, this particular result does not undermine the research findings; on the contrary, they proof that age does not influence the perceptions of the psychological contract a position that needs further corroboration in future studies.

It is worth noting that in this current study, psychological contract moderated the relationships between age and organizational commitment and contributed 16.5 percent of the variance in the relationship between age and employee commitment (Table 5.14). This relationship was positive implying that as age increases then the people tend to have more experience and a wider schema from which to interpret organizational exchanges and thereby they can determine to stay or leave the organization depending on the extent to which they perceive that the psychological contract is fulfilled, breached or violated. The combined mean for the psychological inventory was 2.6 implying a violation of the psychological contract. The combined mean for organizational commitment was 2.72 (Table 4.26) implying employees were committed to their organizations. This result has practical significance because ordinarily people will weigh the relationship with an employer to determine whether it benefits them to continue staying longer or else leave. The current findings are similar to those found by Pate et al (2003) which indicate that if employees perceive an unfulfilled psychological contract they will withdraw their citizenship behaviours reduce commitment and increase their cynicism towards the employer.

Hypothesis $3 \mathrm{~b}$ which stated that the strength of the relationship between age and employee outcomes depends on organizational justice was accepted implying that perceptions of justice moderated the relationship between age and employee outcomes. The findings are presented in Table 5.19 where $r=.390, .271, .138, .499$, for organization commitment, trust, OCB and job satisfaction respectively when organization justice is included and 
$\mathrm{r}=.279, .114, .125, .311$, for organization commitment, trust, OCB and job satisfaction respectively when organization justice is excluded. The extant literature did not show any similar research finding. This can be explained by inferring that age has implications for experience and experiences come in handy when individuals have to make judgments for justice and injustice when undergoing organizational events. This result is a contribution the study is making to the field of knowledge.

\section{Conclusions}

The study found no statistically significant relationships between employee age and employee outcomes. This result puts to question the emphasis laid upon the age factor in organizational decisions such as recruitment and promotion. It also puts in doubt the influence of age on organizational performance since it does not have significant influence on the antecedents of employee performance such as commitment and job satisfaction. It can be concluded that less emphasis should be laid on age when making organizational decisions. However, this conclusion should be understood in view of the fact that the findings contradict other previous findings which found significant relationships. The other studies were essentially in different contexts and therefore it will be prudent to accept this finding in the context of Kenyan public corporations. Further research is needed to corroborate these findings and this is a significant contribution the study has made to the existing body of knowledge.

it can be concluded that the size of an organization matters when dealing with employees and that human resources practices are crucial in influencing the outcomes of employees in organizations. The study is adding to the existing body of knowledge on the role that human resource practices play in organizations. On the role played by organization size the study is making a new contribution to the body of knowledge.

\section{References}

[1]. Aggarwal, U. and Bhargava S. (2009) "Reviewing the Relationship between Human resource Practices and Psychological Contract and their Impact on Employee Attitude and Behaviour" Journal of European Industrial Training Vol.33 No.1 pp. 4-31

[2]. Antonides G. (2 ${ }^{\text {nd }}$ edition). (1996). Psychology in Economics and Business - An introduction to Economic Psychology. Kluwer Academic Publishers.

[3]. Aube C., Rousseau V. and Morin E.M.(2007) "Perceived organizational support and organizational commitment: the moderating effect of locus of control and work autonomy" Journal of Managerial Psychology Vol. 22 No.5 pp. 479-495

[4]. Bernal J.G., Castel A.G., Navarro M.M. and Torres P. R (2005) "Job satisfaction: empirical evidence of gender differences." Women in management Review Vol. 20 No. 4 pp. 279-288

[5]. Chew J. and Chan C. (2008) "Human Resource Practices, Organizational Commitment and Intention to Stay" International Journal of Manpower Vol. 29 No.6 pp.503-522

[6]. Edgar, F. \&Geare, A. (2004). Employee Demographics in Human Resource Management Research, Research and Practice in Human Resource Management, 12(1), 61-91.

[7]. Ekamper P. (1997) "Future age conscious manpower planning in the Netherlands: From early retirement to a new perspective on the elderly? International Journal of Manpower, Vol.18 No.3 pp.232-247

[8]. Elizur D. and Kaslowsky M. (2001) "Work values and organizational commitment" International Journal of Manpower" Vol. 20 No.6 pp.343-360

[9]. Foote D.A, Seipel J.S., Johnson N.B. and Duffy M.K. (2005) "Employee commitment and organizational policies" Management Decision Vol. 43 No.2 pp. 203-219

[10]. Guest D.E and Conway N. (2002) "Pressure at work and the psychological contract" London CIPD.

[11]. Hickson C. and Oshagbemi T. (1999) "The effect of age on the satisfaction of academics with teaching and research" International Journal of Social Economics Vol.26 No.4 pp.537-544

[12]. Krejcie R.V. and Morgan D.W (1970) "Determining Sample Size for research activities" Educational and Psychological Measurement Vol.30 pp.607-610

[13]. Lemire L. and Rouillard C. (2005) "An empirical exploration of psychological contract violation and individual behaviour: The case of Canadian Federal civil servants in Quebec" Journal of Managerial Psychology, Vol.20 No. 2 pp. 150-163

[14]. Lin S. and Chang J. (2005) "Goal orientation and organizational commitment as explanatory factors of employees' mobility" Personnel Review Vol. 34 No. 3 pp. 331-353

[15]. Murphy G., Athanasou J. and King N. (2002) "Job satisfaction and organizational citizenship behaviour" Journal of managerial Psychology Vol. 17 No.4 pp. 287-297

[16]. Nirmala C.M. and Akhilesh B.K. (2006) "An attempt to redefine organizational justice in a rightsizing environment" Journal of Organizational Change Management, Vol.19 No. 2 pp.136-153

[17]. Nurse L. and Devonish D. (2007) “Grievance management and its links to workplace justice” Employee relations, Vol.29 No. 1

[18]. Oshagbemi T. (2004) “Age influences on the leadership styles and behaviour of managers” Employee Relations Vol.26. No.1 pp.1429

[19]. Pate J. (2006) "The changing contours of the psychological contract: Unpacking context and circumstances of breach" Journal of European Industrial Training, vol.30 No.1 pp.32-47

[20]. Pate J., Martin G. and McGoldrick J. (2003) "The impact of psychological contract violation on employee attitudes and behaviour" Employee Relations Vol. 25 No. 6 pp.557-573

[21]. Patrickson M. and Hartmann L. "Australia's ageing population: Implication for Human Resource Management." International Journal of Manpower Vol. 16 No. 5/6 pp. 34- 46

[22]. Podsakoff P.M, Mackenzie S.B., Paine J.B., and Bachrach D.G. (2000) "Organizational Citizenship Behaviours: A Critical Review of the Theoretical and Empirical Literature and Suggestions for Future Research" Journal of Management Vol. 26 No.3 pp.513-563

[23]. Rahim M.A., Magner N.R., Antonioni D. and Rahman S. (2001) "Do justice relationships with organization-directed reactions differ across U.S. and Bangladesh employees?” The international Journal of Conflict management, Vol. 12 No. 4 pp.333-349 
[24]. Robinson S.L (1996) "Trust and Breach of the Psychological Contract" Administrative Science Quarterly retrieved from http://www.findarticles.com

[25]. Roos G., Fernstrom L. and Pike S (2001) Human Resource Management and Business Performance Measurement Measuring Business Excellence Vol. 8 No.1 pp. 28-37

[26]. Saunders M.N.K. and Thornhill A. (2003) "Organizational justice, trust and the management of change: An exploration" Personnel Review, Vol.32 No.3 pp.360-375

[27]. Saunders M.N.K. and Thornhill A. (2006) "Forced employment contract change and the psychological contract" Employee Relations, Vol.28 No.5 pp.449-467

[28]. Scott K. D. and Cook B. (1981) "The Relationship between Employee Age and Interpersonal Trust within an Organizational Context"

[29]. Silva P. (2006) "Effects of disposition on hospitality employee job satisfaction and commitment" Journal of Contemporary Hospitality Management Vol. 18 No. 4 pp 317-328

[30]. Singh V. and Vinnicombe S. (2000) "What does commitment really mean? Views of UK and Swedish engineering managers." Personnel Review Vol.29 No. 2pp. 228 - 258

[31]. Smithson J. and Lewis S. (2000) "Is job insecurity changing the psychological contract?" Personnel Review, Vol.29 No. 6 pp.680702

[32]. Suazo Mark M. (2009) "The mediating role of psychological contract violation on the relations between psychological contract breach and work related attitudes and behaviours" Journal of Managerial Psychology Vol. 24 No.2 pp. 136-160

[33]. Taormina R.J. (1999) "Predicting employee commitment and satisfaction: the relative effects of socialization and demographics" International Journal of Human Resource Management, Vol. 10 No. 6 pp. 1060-1076

[34]. Tu L., Plaisent M., Bernard P. and Maguigara L. (2005) International Journal of Educational Management Vol.19 No. 3 pp.259267

[35]. Whitener E.M., Brodt S.E., Korsgaard M.A., and Werner J.M. (1998) "Managers as Initiators of Trust: An Exchange Relationship framework for Understanding Managerial Trustworthy Behaviour” Academy of Management Review Vol.23 No.3 pp.513-530 